Hossein Rafizadeh

Farhad Azimifar

Puya Foode

Mohammad Reza Foudeh

Mohammad Keymanesh

DOI: $10.21278 /$ TOF.41202

ISSN 1333-1124

eISSN 1849-1391

\title{
WRINKLING PREDICTION IN DEEP DRAWING BY USING RESPONSE SURFACE METHODOLOGY AND ARTIFICIAL NEURAL NETWORK
}

\begin{abstract}
Summary
The objective of this study is to predict influences of tooling parameters such as die and punch radius, blank holder force and friction coefficient between the die and the blank surfaces in a deep drawing process on the wrinkling height in aluminium AA5754 by using the response surface methodology (RSM) and an artificial neural network (ANN). The 3D finite element method (FEM), i.e. the Abaqus software, is employed to model the deep drawing process. In order to investigate the accuracy of this model, the results are compared with experimental results. The data derived from the FEM are used for modelling the RSM and training an ANN. Finally, the RSM and ANN outputs are compared so as to select the best model. The results of the two methods are promising and it is found that the ANN results are more accurate than the RSM results.
\end{abstract}

Key words: $\quad$ ANN, deep drawing, FEM, RSM, wrinkling

\section{Introduction}

The deep drawing process is a significant process in sheet metal forming which is extensively used in industry for converting sheet metal blank to hollow parts without seem at high production rates. One of the predominant and deleterious effects in deep drawing is wrinkling which is induced by plastic instability. The effect of various factors that lead to wrinkling occurrence are: the blank holder force, the geometrical parameters of the die such as die radius and punch radius, the friction coefficient between die and workpiece, the workpiece geometry, the mechanical properties of material etc. Since the wrinkling height is a determinative factor in the evaluation of products, the prediction of this parameter before the process is carried out can prevent material wastage. Methods such as RSM and ANN have particular computational properties that make them suited for particular applications such as prediction. Nowadays, most studies related to the deep drawing process investigate the optimization in order to reduce the wrinkling height. A comprehensive literature review has been done on various aspects of the deep drawing process in the field of prediction and wrinkling (Table 1). 
Table 1 Literature review

\begin{tabular}{|c|c|c|c|c|c|}
\hline $\begin{array}{l}\text { Investigator } \\
\text { No. }\end{array}$ & Material & Technique & $\begin{array}{l}\text { Input } \\
\text { parameters }\end{array}$ & $\begin{array}{l}\text { Output } \\
\text { response }\end{array}$ & Finding of the study \\
\hline $\begin{array}{l}\text { 1. Singh and } \\
\text { Gupta (2010) [1] }\end{array}$ & IF & $\begin{array}{l}\text { SVR } \\
\text { Modelling, } \\
\text { ANN and } \\
\text { FEM }\end{array}$ & $\begin{array}{l}\text { Design, } \\
\text { Process and } \\
\text { Material }\end{array}$ & Thickness & $\begin{array}{l}\text { The SVR worked significantly well and } \\
\text { predicted a large portion of thickness strains } \\
\text { correctly, especially in the wall region of the } \\
\text { drawn cup. }\end{array}$ \\
\hline
\end{tabular}

\begin{tabular}{|c|c|c|c|}
\hline $\begin{array}{l}\text { 2. Saxena and } \\
\text { Dixit (2010) [2] }\end{array}$ & $\begin{array}{l}\text { Aluminium } \\
\text { (AA2090- } \\
\text { T3, } \\
\text { AA6111- } \\
\text { T4) }\end{array}$ & $\begin{array}{l}\text { Bifurcation } \\
\text { Criterion }\end{array}$ & $\begin{array}{l}\text { Material } \\
\text { Properties and } \\
\text { Tool } \\
\text { Dimension }\end{array}$ \\
\hline $\begin{array}{l}\text { 3. Morovvati et } \\
\text { al. (2010) [3] }\end{array}$ & $\begin{array}{l}\text { Aluminium } \\
\text { (A13105, } \\
\text { Al1100) and } \\
\text { Steel } \\
\text { (SUS304) }\end{array}$ & $\begin{array}{l}\text { Analytical } \\
\text { Method } \\
\text { (energy } \\
\text { method) and } \\
\text { FEM }\end{array}$ & $\begin{array}{l}\text { Material } \\
\text { properties of } \\
\text { two layer } \\
\text { sheets }\end{array}$ \\
\hline
\end{tabular}

Wrinkling An increase in the blank holder pressure or the sheet thickness delays the onset of wrinkling. The maximum cup height at the onset of wrinkling increases with an increase in the die profile radius or punch profile radius. The sheet anisotropy, in general, delays the onset of wrinkling.

Wrinkling The minimum required blank holder force to prevent wrinkling in the case of A.I. lay-ups is higher than the one in the case of S.I. layups. The forming force of A.I. lay-ups is greater than the one of S.I. lay-ups. The resultant yield stress of two-layer sheets is a function of the yield stress of their components.

$\begin{array}{llll}\begin{array}{l}\text { 4. Kim et al. } \\ \text { (2001) [4] }\end{array} & \begin{array}{l}\text { Aluminium } \\ \text { (A6111-T4) }\end{array} & \begin{array}{l}\text { Bifurcation } \\ \text { Criterion }\end{array} & \begin{array}{l}\text { Tool } \\ \text { Dimensions }\end{array} \\ \begin{array}{l}\text { 5. Correia and } \\ \text { Ferron (2004) [5] }\end{array} & \text { Mild Steel } & \begin{array}{l}\text { Bifurcation } \\ \text { Criterion and } \\ \text { FEM }\end{array} & \begin{array}{l}\text { Plastic } \\ \text { Anisotropy } \\ \text { Of Material }\end{array}\end{array}$

Wrinkling As the ratio of the punch increases the wrinkling initiation is retarded and fracture takes place earlier near to the major axis.

Wrinkling The numerical predictions are in good agreement with experiments. They also compare reasonably well with the analytical predictions of wrinkling, concerning both the number of wrinkles and their angular location relative to the orthotropic axes of the material.

\begin{tabular}{|c|c|c|c|c|}
\hline $\begin{array}{l}\text { 6. Zeng and } \\
\text { Mahdavian } \\
\text { (1998) [6] }\end{array}$ & Aluminium & $\begin{array}{l}\text { Theoretical } \\
\text { Model } \\
\text { (Equilibrium } \\
\text { Moment) }\end{array}$ & Temperature & Wrinkling \\
\hline $\begin{array}{l}\text { 7. Khelifa and } \\
\text { Oudjene (2008) } \\
\text { [7] }\end{array}$ & Steel & $\begin{array}{l}\text { Plasticity } \\
\text { Damage } \\
\text { Model and } \\
\text { FEM }\end{array}$ & $\begin{array}{l}\text { Punch Travel } \\
\text { and Punch } \\
\text { Stroke }\end{array}$ & Damage \\
\hline
\end{tabular}

The results of the theoretical solution are compared with the experimental results at ambient and elevated temperatures and good agreement is found.

The developed model allows for prediction of damage in the workpiece during stamping or forming. This model also predicts the elastic, plastic and hardening behaviors neglected in approaches which do not use a coupled technique.

$\begin{array}{lll}\begin{array}{l}\text { 8. Sheng et al. Steel } \\ \text { (2004) [8] }\end{array} & \text { Adaptive FEM Punch Stroke } & \text { Blank } \\ & \text { Holder } \\ & \text { Force }\end{array}$

Such a blank holder force profile can improve the formability of the conical cup drawing process, i.e. by increasing (a) the failure-free drawing depth and (b) the uniformity of the wall thinning distribution. The proposed method can be further improved to determine nearly optimum blank holder force profiles for drawing more complex parts, such as rectangular pan or nonsymmetric automotive stampings.

$\begin{array}{lllll}\begin{array}{l}\text { 9. Zein et al. } \\ \text { (2014) [9] }\end{array} & \text { Mild steel } & \text { FEM } & \text { Friction and } & \text { Spring } \\ & & & \text { Tool } & \text { Back and } \\ & & \text { Dimensions } & \text { Thinning }\end{array}$

The die shoulder radius is recommended to be about 10 times sheet thickness. The punch nose radius is recommended to be greater than 4 times sheet thickness. The thicker sheet metal is softer due to its increased volume, which increases the thinning and reducing of the spring back in sheet metal. The fluid lubricant is more suitable for the punch/blank interface to reduce the thinning 
Artificial Neural Network

\begin{tabular}{llllll}
\hline $\begin{array}{l}\text { Investigator } \\
\text { No. }\end{array}$ & Material & Technique & $\begin{array}{l}\text { Input } \\
\text { parameters }\end{array}$ & $\begin{array}{l}\text { Output } \\
\text { response }\end{array}$ & Finding of the study \\
\hline $\begin{array}{l}\text { 10. } \\
\text { Padmanabhan et } \\
\text { al. (2007) [10] }\end{array}$ & $\begin{array}{l}\text { Stainless } \\
\text { Steel }\end{array}$ & $\begin{array}{l}\text { FEM and } \\
\text { Taguchi } \\
\text { Method }\end{array}$ & $\begin{array}{l}\text { Die Radius, } \\
\text { Friction and } \\
\text { Blank Holder }\end{array}$ & $\begin{array}{l}\text { Deep } \\
\text { Drawing } \\
\text { Process }\end{array}$ & $\begin{array}{l}\text { and the spring back in the cup. } \\
\text { The die radius (89.2\%) has major influence } \\
\text { on the deep-drawing process, followed by the } \\
\text { friction coefficient }(6.3 \%) \text { and the blank } \\
\text { holder force (4.5\%). }\end{array}$ \\
$\begin{array}{l}\text { 11. Gusel et.al. } \\
(2015)[1]\end{array}$ & Copper & $\begin{array}{l}\text { Genetic } \\
\text { programming } \\
\text { and regression } \\
\text { analysis }\end{array}$ & $\begin{array}{l}\text { Drawing } \\
\text { speed, die } \\
\text { angle, rod } \\
\text { dimension }\end{array}$ & Elongation & $\begin{array}{l}\text { High precise models developed through GP } \\
\text { approach can provide results with less } \\
\text { experiments/simulations. GP models have } \\
\text { lower deviation compared to regression } \\
\text { models. }\end{array}$ \\
\hline
\end{tabular}

It is evident from the literature review that almost nothing has been reported on the prediction of the effect of the parameters such as die radius, punch radius, blank holder force and friction coefficient on wrinkling in aluminium AA5754 by RSM and ANN. Fig. 1 shows a 2D schematic of the deep drawing process including these effective parameters.

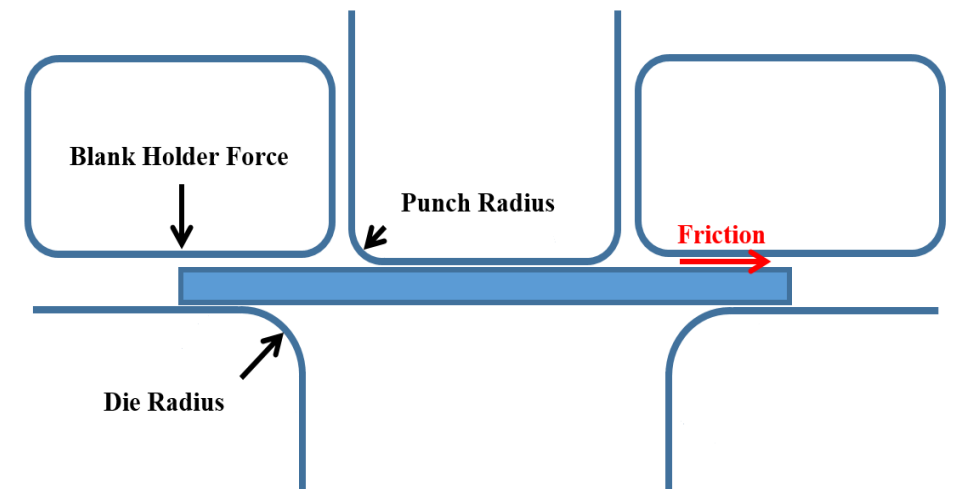

Fig. 1 2D schematic of deep drawing process including effective parameters

\section{Methodology}

In order to predict the wrinkling height, the following steps are carried out:

- Design of Experiment (DOE) is used for designing tests.

- The designed tests are done by applying the FEM by means of the Abaqus software.

- The FEM results are prepared to specify inputs for RSM and ANN to predict the wrinkling height.

- The results of RSM and ANN are compared with the FEM outputs to select the best method for prediction.

\subsection{Design of Experiment}

The aim of this study is to predict the wrinkling height by changing four variables including die radius $\left(R_{D}\right)$, punch radius $\left(R_{P}\right)$, friction coefficient $(\mu)$ and blank holder force $(B H F)$ that have the strongest effect on the wrinkling height $(W H)$. In the previous study by these authors the influence of these variables was investigated [12], so in this paper, the effective range of each parameter is considered in the design of the tests. For each factor five levels are defined as summarized in Table 2. The upper level of a factor is coded as +2 , the center level as 0 , and the lower level as -2 . 
Table 2 Factors and their levels

\begin{tabular}{lccllllll}
\hline Factor & Notation & Unit & \multicolumn{7}{l}{ Factor levels } \\
\cline { 5 - 8 } & & & -2 & -1 & 0 & 1 & 2 \\
\hline Die radius & $R_{D}$ & $\mathrm{~mm}$ & 14 & 15 & 16 & 17 & 18 \\
Punch radius & $R_{P}$ & $\mathrm{~mm}$ & 16 & 18 & 20 & 22 & 24 \\
Friction coefficient & $\mu$ & - & 0.04 & 0.06 & 0.08 & 0.10 & 0.12 \\
Blank holder force & $B H F$ & $\mathrm{MPa}$ & 0.80 & 0.95 & 1.10 & 1.25 & 1.40 \\
\hline
\end{tabular}

The process of selecting tests is known as the design of experiment (DOE). In this paper, the central composite design (CCD) is employed for training data. This method is rotatable and created easily from $2^{\mathrm{k}}$ factorials. The CCD for four parameters includes 25 samples that consist of 16 corner points, 8 axial points and 1 centre point. Table 3 shows the data set in a coded form. These data are used by the Abaqus software so as to specify $W H$.

\subsection{FEM Modelling}

In the previous study by the authors, a 3D deep drawing process has been simulated using a commercial finite element code, Abaqus, and verified by experimental tests. The dimensions of blank, square cup and hydraulic press are considered as specified in the mentioned study [12] and Al 5754, whose properties are presented in Fig. 2, is chosen for the blank.

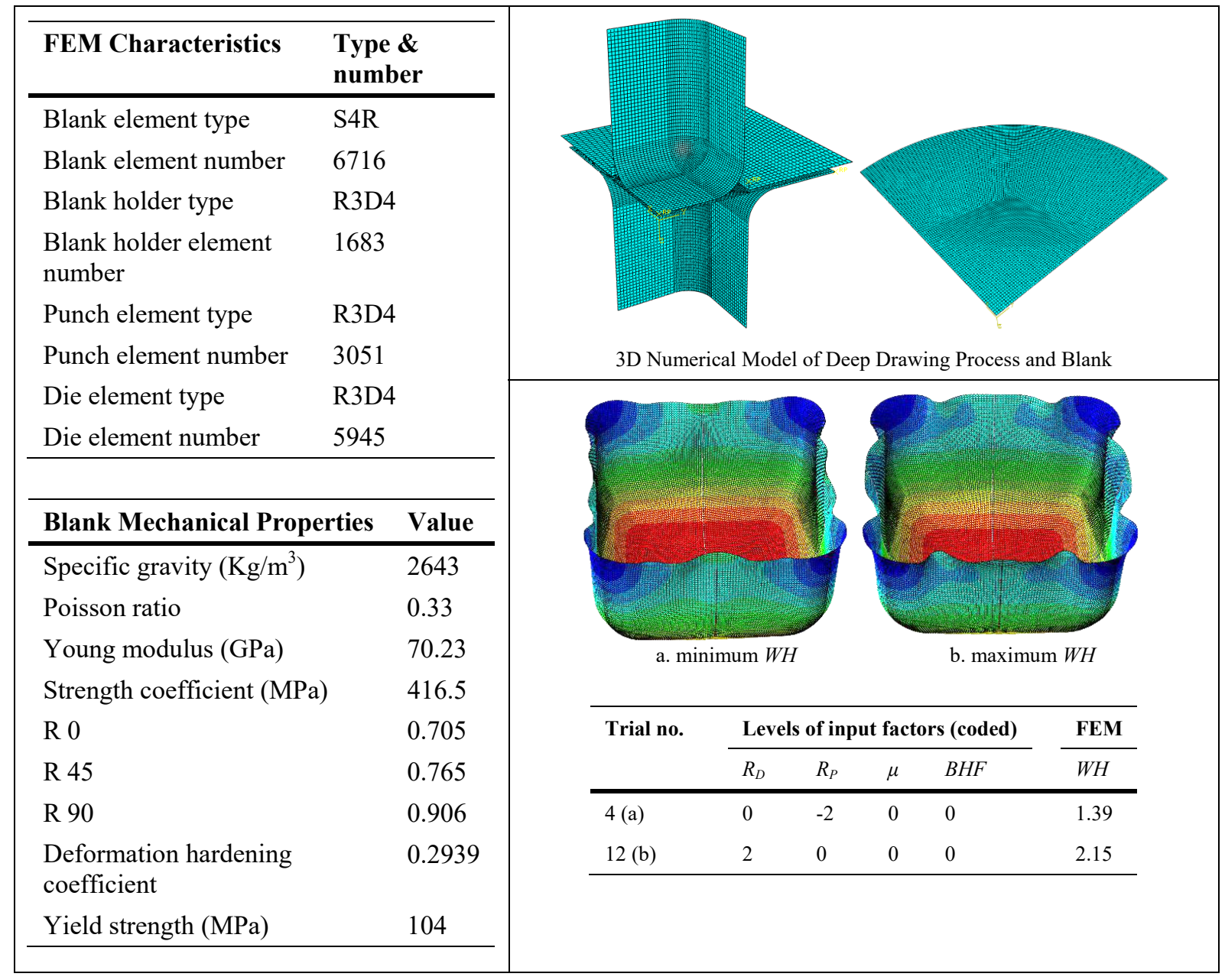

Fig. 2 FEM modelling 
Fig. 2 shows the numerical model created by the Abaqus software. The output values obtained from the 3D simulation of the deep drawing process with FEM are presented in Table 3.

Table 3 Design matrix for data set in coded form along with FEM results

\begin{tabular}{|c|c|c|c|c|c|c|c|c|c|c|c|}
\hline \multirow[t]{2}{*}{$\begin{array}{l}\text { Trial } \\
\text { no. }\end{array}$} & \multicolumn{4}{|c|}{$\begin{array}{l}\text { Levels of input factors } \\
\text { (coded) }\end{array}$} & \multirow{2}{*}{$\begin{array}{c}\text { FEM } \\
W H\end{array}$} & \multirow[t]{2}{*}{$\begin{array}{l}\text { Trial } \\
\text { no. }\end{array}$} & \multicolumn{4}{|c|}{$\begin{array}{l}\text { Levels of input factors } \\
\text { (coded) }\end{array}$} & \multirow{2}{*}{$\begin{array}{c}\text { FEM } \\
W H\end{array}$} \\
\hline & $R_{D}$ & $R_{P}$ & $\mu$ & $B H F$ & & & $R_{D}$ & $R_{P}$ & $\mu$ & $B H F$ & \\
\hline 1 & 0 & 0 & 0 & 0 & 1.71 & 14 & -1 & 1 & 1 & -1 & 1.79 \\
\hline 2 & 1 & 1 & -1 & -1 & 2.01 & 15 & 0 & 0 & 0 & -2 & 1.76 \\
\hline 3 & 0 & 2 & 0 & 0 & 2.05 & 16 & 0 & 0 & 0 & 2 & 1.64 \\
\hline 4 & 0 & -2 & 0 & 0 & 1.39 & 17 & 0 & 0 & -2 & 0 & 1.75 \\
\hline 5 & 1 & -1 & 1 & 1 & 1.62 & 18 & -1 & 1 & -1 & 1 & 1.76 \\
\hline 6 & 1 & -1 & -1 & 1 & 1.67 & 19 & 1 & 1 & -1 & 1 & 1.86 \\
\hline 7 & -1 & 1 & 1 & 1 & 1.69 & 20 & 0 & 0 & 2 & 0 & 1.56 \\
\hline 8 & 1 & 1 & 1 & 1 & 1.84 & 21 & -1 & -1 & 1 & 1 & 1.43 \\
\hline 9 & -1 & -1 & 1 & -1 & 1.44 & 22 & -1 & 1 & -1 & -1 & 1.85 \\
\hline 10 & 1 & 1 & 1 & -1 & 1.95 & 23 & -1 & -1 & -1 & -1 & 1.49 \\
\hline 11 & -1 & -1 & -1 & 1 & 1.48 & 24 & 1 & -1 & 1 & -1 & 1.69 \\
\hline 12 & 2 & 0 & 0 & 0 & 2.15 & 25 & 1 & -1 & -1 & -1 & 1.72 \\
\hline
\end{tabular}

\subsection{RSM Modelling}

RSM is a combination of mathematical and statistical methods used in an empirical study of relationships and optimization, where several independent variables influence a dependent variable or response. RSM is a model building technique based on the statistical DOE and least square error fitting [13]. RSM, which creates polynomial models for the available data, is given in Eq. 1.

$$
Y_{u}=b_{0}+\sum_{i=1}^{k} b_{i} X_{i}+\sum_{i=1}^{k} b_{i i} X_{i}^{2}+\sum_{j>k}^{k} b_{i j} X_{i} X_{j}
$$

In this equation, $Y_{u}$ is the output parameter, $b_{0}$ is the constant coefficient, $b_{i i}$ is the second order coefficient and $b_{i j}$ is the interaction coefficient. In Fig. 3, WH versus input parameters is illustrated as it is indicated, $W H$ increases with an increase in $R_{D}$ and $R_{P}$ and decreases with an increase in $\mu$ and $B H F$. The model fitted to the data is given in Eq. 2

$$
\begin{aligned}
& W H=-2.90+2.71 B H F+0.305 R_{P}-0.187 R_{D}+1.8 \mu \\
& -0.199 B H F^{2}+0.00018 R_{P}^{2}+0.0174 R_{D}^{2}-38.4 \mu^{2} \\
& -0.0707 B H F^{*} R_{P}-0.069 B H F^{*} R_{D}+0.12 B H F^{*} \mu \\
& -0.00975 R_{P} * R_{D}-0.060 R_{P} * \mu+0.236 R_{D} * \mu
\end{aligned}
$$


H. Rafizadeh, F. Azimifar, P. Foode,

M. R. Foudeh, M. Keymanesh
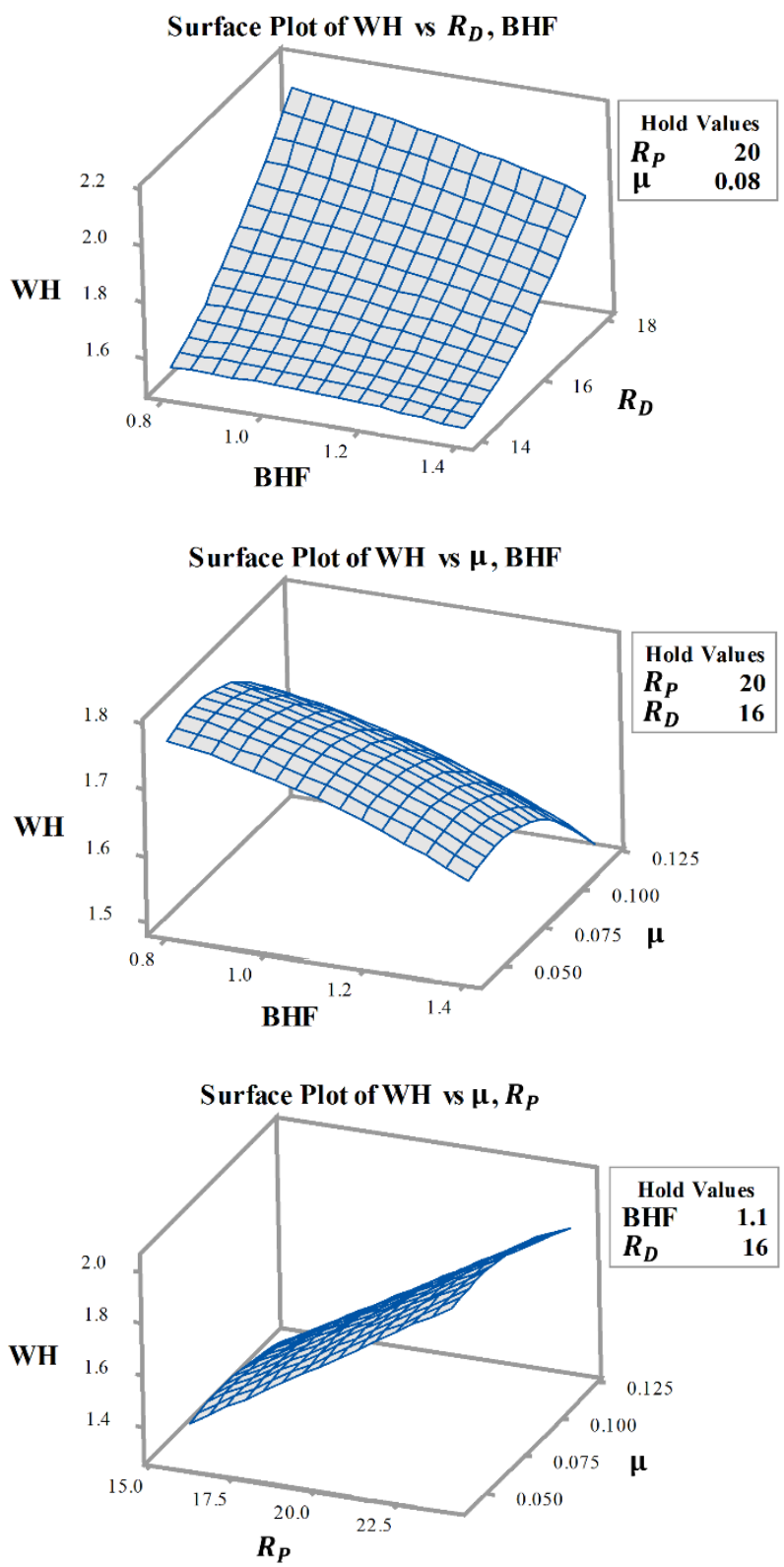

Wrinkling Prediction in Deep Drawing by Using Response Surface Methodology and Artificial Neural Network
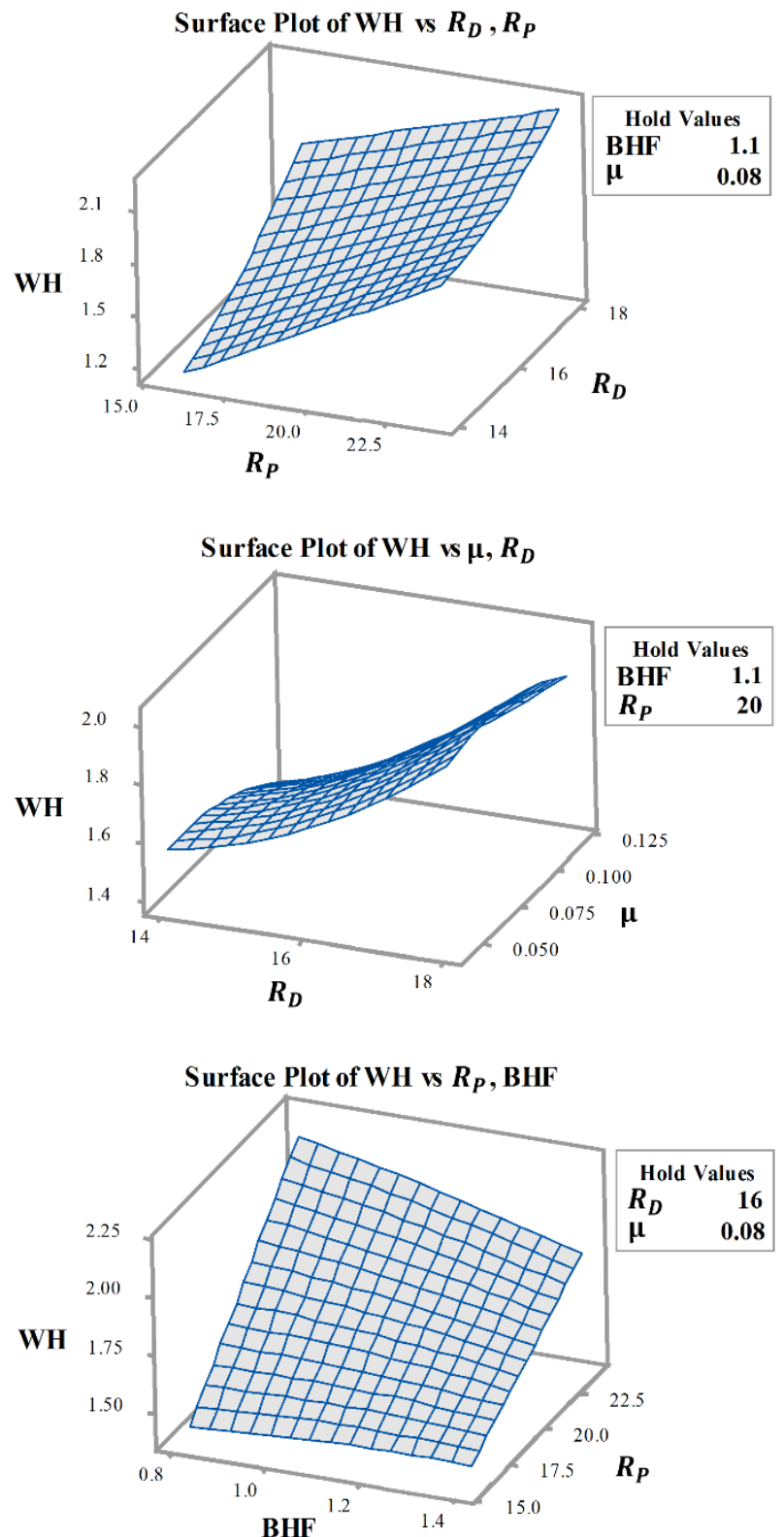

Fig. $3 W H$ versus input parameters

A sensitivity analysis is run to further validate each model and examine the contribution of an input variable to the output for each individual case in the training data. As Fig. 4 shows, $R_{P}$ and $\mu$ have the most and least influence on the output, respectively. Furthermore, the sensitivity analysis displays that by increasing $B H F$ and $\mu, W H$ decreases and by increasing $R_{P}$ and $R_{D}, W H$ grows.

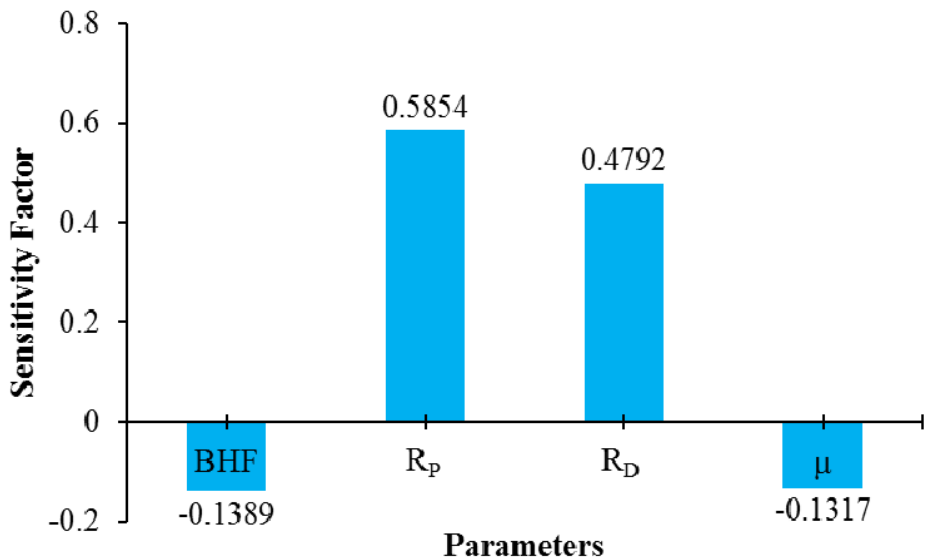

Fig. 4 RSM sensitivity analysis 
Finally, Table 4 is presented with the aim of comparing the RSM to the FEM results based on 25 input data.

Table 4 Comparison between RSM and FEM results

\begin{tabular}{cccc}
\hline Trial no. & \multicolumn{1}{l}{$\boldsymbol{H} \boldsymbol{l}$} & Error \\
\cline { 2 - 3 } & FEM & RSM & \\
\hline 1 & 1.71 & 1.70 & 0.01 \\
2 & 2.01 & 2.04 & -0.03 \\
3 & 2.05 & 2.00 & 0.05 \\
4 & 1.39 & 1.41 & -0.02 \\
5 & 1.62 & 1.64 & -0.02 \\
6 & 1.67 & 1.69 & -0.02 \\
7 & 1.69 & 1.66 & 0.03 \\
8 & 1.84 & 1.85 & -0.01 \\
9 & 1.44 & 1.38 & 0.06 \\
10 & 1.95 & 1.98 & -0.03 \\
11 & 1.48 & 1.44 & 0.04 \\
12 & 2.15 & 2.00 & 0.15 \\
13 & 1.43 & 1.53 & -0.10 \\
\hline
\end{tabular}

\begin{tabular}{|c|c|c|c|}
\hline \multirow[t]{2}{*}{ Trial no. } & \multicolumn{2}{|l|}{$W H$} & \multirow[t]{2}{*}{ Error } \\
\hline & FEM & RSM & \\
\hline 14 & 1.79 & 1.75 & 0.04 \\
\hline 15 & 1.76 & 1.75 & 0.01 \\
\hline 16 & 1.64 & 1.61 & 0.03 \\
\hline 17 & 1.75 & 1.70 & 0.05 \\
\hline 18 & 1.76 & 1.74 & 0.02 \\
\hline 19 & 1.86 & 1.91 & -0.05 \\
\hline 20 & 1.56 & 1.57 & -0.01 \\
\hline 21 & 1.43 & 1.37 & 0.06 \\
\hline 22 & 1.85 & 1.83 & 0.02 \\
\hline 23 & 1.49 & 1.45 & 0.04 \\
\hline 24 & 1.69 & 1.69 & 0.00 \\
\hline 25 & 1.72 & 1.74 & -0.02 \\
\hline
\end{tabular}

\subsection{ANN Modelling}

A neural network is a parallel processing architecture consisting of a large number of interconnected processors, called neurons, organized in layers [14]. The performance of a neural network depends mainly on its weights of connection. In general, each neuron can be connected with all other neurons. For manufacturing processes where no satisfactory analytic model exists or a low order empirical polynomial model is inappropriate, neural networks offer a good alternative approach [15].

Recently, many different neural network models have been developed. They include Perceptron, Hopfield and Hamming Network. Various types of algorithms used for training ANNs include Backpropagation, Delta Learning Rule, Hebb Learning Rule and Bayesian Regularization Algorithm [16]. There are several transfer functions such as Hardlim, Purelin and Logsig function utilized in neural network models.

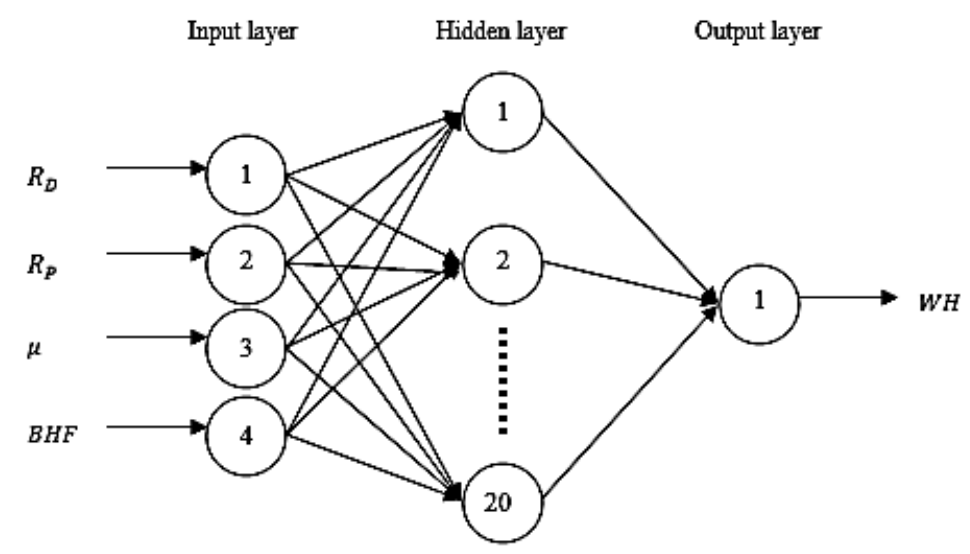

Fig. 5 The architecture of ANN for $W H$ models

In this paper, an ANN is also considered in order to assess the best method for the prediction of $W H$. The neural network that is employed is the multilayer perceptron that learned by using the Bayesian Regularization Algorithm. The data that were used for training 
and testing the ANN are the same as the data used for RSM (the number of training and testing data is 25 and 5 , respectively). Fig. 5 shows the architecture of the neural network utilized for the prediction of WH. As Fig. 5 shows, the hidden layer has 20 neurons with the Logsig function. The function of the output layer, Hardlim, is taken into account. The learning factors of the training network are presented in Table 5.

Table 5 Learning factors

\begin{tabular}{ll}
\hline Learning factors & Value \\
\hline Learning rate $(\eta)$ & 0.05 \\
Momentum constant & 0.9 \\
Learning rate increment & 1.1 \\
Maximum number of epochs & 3000 \\
Target for MSE & 0.0001 \\
\hline
\end{tabular}

The principal steps in the training process are given below:

1. Initialize all of the weights of the links to random values.

2. Present the input-desired output patterns one by one, updating the weights each time using Eq. 3.

$$
w_{j i(n+1)}=w_{j i(n)}+\eta \delta_{p j} o_{p i}+\alpha \Delta w_{j i(n)}
$$

Where $w_{j i}$ is the weight of the link connecting neuron $j$ to $i, n$ is the learning step, $\eta$ is the learning rate, $\alpha$ is the momentum constant, and $\delta_{p j}$ is the error term.

3. After presenting all of the patterns, if $\hat{Y}$ is a vector of $n$ predictions, and $Y$ is the vector of the observed values corresponding to the inputs to the function which generated the predictions, then the MSE of the predictor can be estimated by:

$$
M S E=\frac{1}{n} \sum_{i=1}^{n}\left(\hat{Y}_{i}-Y_{i}\right)^{2}
$$

4. If $\left(M S E<M S E_{\text {target }}\right)$ or $\left(\right.$ epochs $>$ epochs $\left.s_{\max }\right)$, then stop,

otherwise, go to step 2.

The variation of the MSE during the training is shown in Fig. 6. The MSE target is achieved in 140 epochs and the training is terminated. As Fig. 6 illustrates, the best training performance is 0.0030136 at epoch 113 and that is acceptable and promising.

For calculating the sensitivity of each parameter in the $\mathrm{ANN}$, the specified parameter has maximum and minimum quantity and other parameters have average quantity. In this condition, the sensitivity is a difference of output in the normalized situation. Fig. 7 shows the sensitivity analyzed by using the ANN. As Fig. 7 shows, $R_{P}$ and $\mu$ have the most and the least influence on the

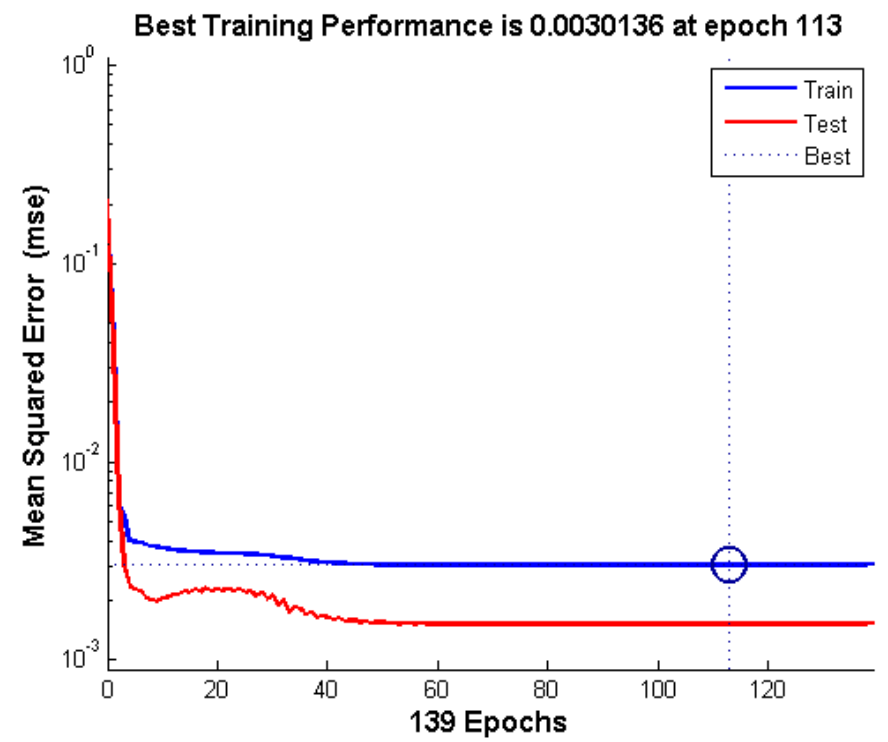
output, respectively.

Fig. 6 Variation of MSE during ANN training 


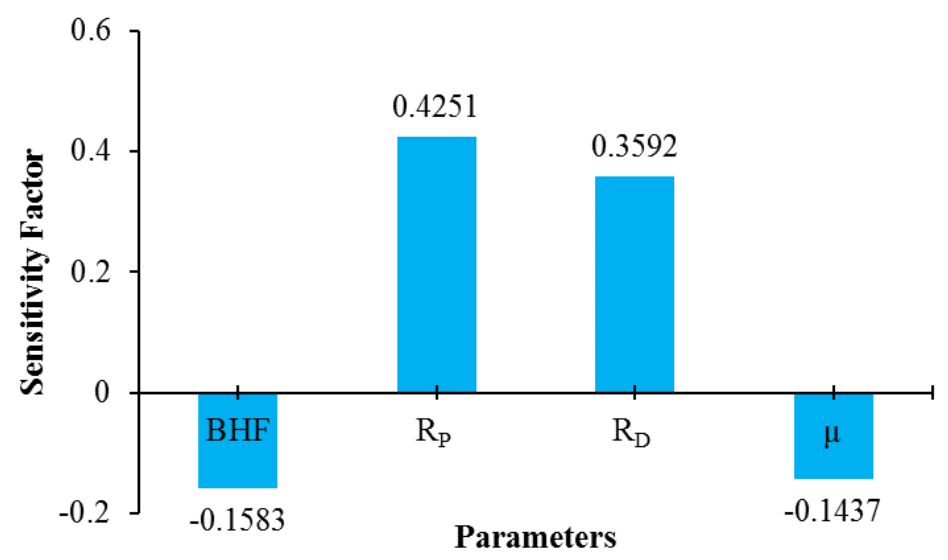

Fig. 7 ANN sensitivity analysis

Finally, Table 6 is presented with the aim of comparing the ANN results with the FEM results regarding 25 input data.

Table 6 Comparison between RSM and ANN results

\begin{tabular}{clll}
\hline Trial no. & $\boldsymbol{W} \boldsymbol{H}$ & & Error \\
\cline { 2 - 3 } & FEM & ANN & \\
\hline 1 & 1.71 & 1.71 & 0.00 \\
2 & 2.01 & 2.05 & -0.04 \\
3 & 2.05 & 2.01 & 0.04 \\
4 & 1.39 & 1.40 & -0.01 \\
5 & 1.62 & 1.62 & 0.00 \\
6 & 1.67 & 1.68 & -0.01 \\
7 & 1.69 & 1.66 & 0.03 \\
8 & 1.84 & 1.88 & -0.04 \\
9 & 1.44 & 1.43 & 0.01 \\
10 & 1.95 & 1.98 & -0.03 \\
11 & 1.48 & 1.49 & -0.01 \\
12 & 2.15 & 2.02 & 0.13 \\
13 & 1.43 & 1.45 & -0.02 \\
\hline
\end{tabular}

\begin{tabular}{|c|c|c|c|}
\hline \multirow[t]{2}{*}{ Trial no. } & \multicolumn{2}{|l|}{$W H$} & \multirow[t]{2}{*}{ Error } \\
\hline & FEM & ANN & \\
\hline 14 & 1.79 & 1.74 & 0.05 \\
\hline 15 & 1.76 & 1.77 & -0.01 \\
\hline 16 & 1.64 & 1.65 & -0.01 \\
\hline 17 & 1.75 & 1.78 & -0.03 \\
\hline 18 & 1.76 & 1.71 & 0.05 \\
\hline 19 & 1.86 & 1.92 & -0.06 \\
\hline 20 & 1.56 & 1.63 & -0.07 \\
\hline 21 & 1.43 & 1.41 & 0.02 \\
\hline 22 & 1.85 & 1.82 & 0.03 \\
\hline 23 & 1.49 & 1.49 & 0.00 \\
\hline 24 & 1.69 & 1.69 & 0.00 \\
\hline 25 & 1.72 & 1.77 & -0.05 \\
\hline
\end{tabular}

\section{Comparing RSM and ANN models}

The comparison of both methods demonstrates that ANN is much accurate in making prediction than RSM. The last step of an RSM and an ANN design is the verification of the prediction models on the basis of error function. The multivariable functional approximation by RSM and ANN is evaluated by using a continuous error metric such as the mean squared error (MSE) and the root mean squared error (RMSE). In Table 7 a comparison between two models according to the evaluation method is shown. It is observed that the coefficient of determination, denoted $R^{2}$, of 0.948 and 0.976 for RSM and ANN, respectively, is obtained This amount represents the superiority of ANN over RSM. 
H. Rafizadeh, F. Azimifar, P. Foode,

M. R. Foudeh, M. Keymanesh
Wrinkling Prediction in Deep Drawing by Using Response Surface Methodology and Artificial Neural Network

Table 7 Comparison between two models according to evaluation method

\begin{tabular}{llllll}
\hline \multirow{2}{*}{ Model } & \multicolumn{5}{l}{ Evaluation method } \\
\cline { 2 - 6 } & Average error \% & MSE & RMSE & $\mathrm{R}^{2}$ & $\mathrm{R}^{2}$ (adj) \\
\hline RSM & 2.167 & 0.002 & 0.047 & 0.948 & 0.875 \\
ANN & 1.669 & 0.001 & 0.032 & 0.976 & 0.939 \\
\hline
\end{tabular}

The design matrix along with the FEM, RSM and ANN results for the testing data is shown in Table 8 . It can be seen that the output values predicted by the ANN are closer to the FEM results.

Table 8 Design matrix along with FEM, RSM and ANN results for testing data

\begin{tabular}{lllllllll}
\hline Trial no. & \multicolumn{9}{l}{ Levels of input factors (coded) } & & $\boldsymbol{W H}$ & & \\
\cline { 2 - 5 } \cline { 7 - 9 } & $R_{D}$ & $R_{P}$ & $\mu$ & $B H F$ & & FEM & RSM & ANN \\
\hline 1 & 0 & -2 & 0 & -2 & & 1.39 & 1.38 & 1.40 \\
2 & -2 & 0 & -2 & 0 & & 1.59 & 1.56 & 1.61 \\
3 & 0 & 0 & -2 & -2 & & 1.84 & 1.76 & 1.79 \\
4 & -2 & -2 & 0 & 0 & & 1.19 & 1.16 & 1.20 \\
5 & 2 & -2 & 2 & -2 & & 1.72 & 1.70 & 1.70 \\
\hline
\end{tabular}

Fig. 8 and Fig. 9 illustrate a comparison of the $W H$ error profiles for training and testing data. The maximum absolute percentage error in the ANN prediction is found to be around $5.84 \%$ while in the case of the RSM model, it is around $7.60 \%$. Thus, it can be concluded that the ANN model predicts more accurately than the RSM model.

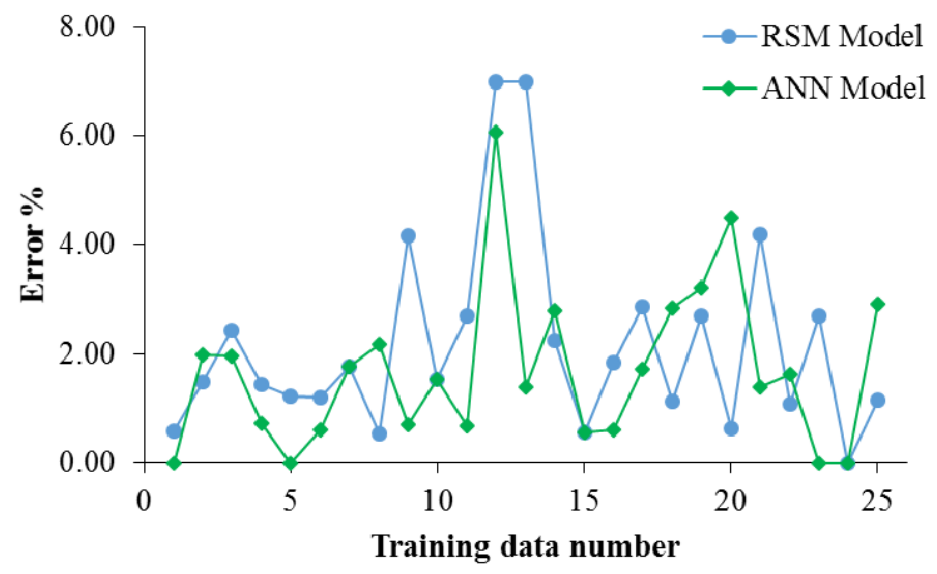

Fig. 8 Comparison of error profiles for $W H$

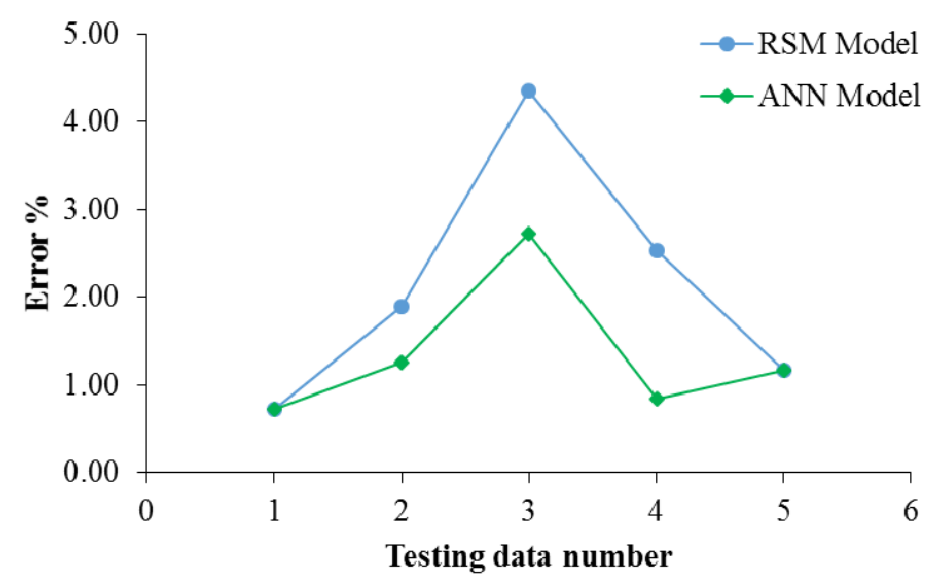

Fig. 9 Comparison of RSM and ANN predictions of $W H$ for testing data 
Wrinkling Prediction in Deep Drawing by Using Response Surface Methodology and Artificial Neural Network
H. Rafizadeh, F. Azimifar, P. Foode, M. R. Foudeh, M. Keymanesh

\section{Conclusions}

This study demonstrates a comparative analysis of the modelling approaches by using RSM and ANN for the $W H$ prediction in deep drawing of aluminium AA5754. The CCD for four parameters including 25 samples is employed to generate the input-output database required for the development of RSM and ANN models.

It has been observed that by decreasing $R_{D}$ and $R_{P}$ and increasing $\mu$ and $B H F, W H$ is reduced, therefore, the optimum value of these parameters is recommended for preventing wrinkling in the deep drawing process.

The performance of the two models is compared based on prediction accuracy. Consequently, the following conclusions are drawn from the present investigation:

- The performance of the ANN model is found to be better compared to the RSM model in terms of the $\mathrm{WH}$ prediction both for the training and the testing data.

- The expense of using the ANN approach is greater than when the RSM approach is used due to time consumption.

- Both approaches show that $R_{P}$ has the strongest effect and $\mu$ has the minimal effect on $W H$.

- The result of the designed ANN and RSM is in agreement with the training and testing data.

Among different trained multilayer perceptron architectures, the 4-20-1 network developed by using the Bayesian Regularization Algorithm is the optimum network model for the $W H$ prediction in deep drawing of aluminum AA5754.

\section{REFERENCES}

[1] Singh SK, Gupta AK (2010) Application of support vector regression in predicting thickness strains in hydro-mechanical deep drawing and comparison with ANN and FEM. CIRP Journal of manufacturing Science and Technology 3(1):66-72. DOI:10.1016/j.cirpj.2010.07.005

[2] Saxena RK, Dixit PM (2010) Prediction of flange wrinkling in deep drawing process using bifurcation criterion. Journal of Manufacturing Processes 12(1):19-29. DOI:10.1016/j.jmapro.2010.01.003

[3] Morovvati MR, Mollaei-Dariani B, Asadian-Ardakani MH (2010) A theoretical, numerical, and experimental investigation of plastic wrinkling of circular two-layer sheet metal in the deep drawing. Journal of Materials Processing Technology 210(13):1738-1747. DOI:10.1016/j.jmatprotec.2010.06.004

[4] Kim JB, Yoon JW, Yang DY, Barlat F (2001) Investigation into wrinkling behavior in the elliptical cup deep drawing process by finite element analysis using bifurcation theory. Journal of Materials Processing Technology 111(1):170-174. DOI:10.1016/S0924-0136(01)00504-0

[5] Correia JD, Ferron G (2004) Wrinkling of anisotropic metal sheets under deep-drawing: analytical and numerical study. Journal of Materials Processing Technology 155:1604-1610. DOI:10.1016/j.jmatprotec.2004.04.270

[6] Zeng XM, Mahdavian SM (1998) Critical conditions of wrinkling in deep drawing at elevated temperature. Journal of Materials Processing Technology 84(1):38-46. DOI: 0.1016/S0924-0136(98)00077-6

[7] Khelifa M, Oudjene M (2008) Numerical damage prediction in deep-drawing of sheet metals. Journal of materials processing technology 200(1):71-76. DOI:10.1016/j.jmatprotec.2007.08.041

[8] Sheng ZQ, Jirathearanat S, Altan T (2004) Adaptive FEM simulation for prediction of variable blank holder force in conical cup drawing. International Journal of Machine Tools and Manufacture 44:487-94. DOI:10.1016/j.ijmachtools.2003.11.001

[9] Zein H, El Sherbiny M, Abd-Rabou M (2014) Thinning and spring back prediction of sheet metal in the deep drawing process. Materials \& Design 53:797-808. DOI:10.1016/j.matdes.2013.07.078

[10] Padmanabhan R, Oliveira MC, Alves JL, Menezes LF (2007) Influence of process parameters on the deep drawing of stainless steel. Finite Elements in Analysis and Design 43(14):1062-1067.

DOI:10.1016/j.finel.2007.06.011 
[11] Gusel, L.; Rudolf, R. \& Brezocnik, M (2015) Genetic Based Approach to Predicting the Elongation of Drawn Alloy. International Journal of Simulation Modelling 14 (1): 39-47. DOI:10.2507/IJSIMM14(1)4.277

[12] Foudeh MR, Daneshmand S, Demirci HI (2014) Investigating aluminum sheet wrinkling during the deep drawing process. Transactions of FAMENA 37(4):43-54.

[13] Myers RH, Montgomery DC, Anderson-Cook CM (2016) Response surface methodology: process and product optimization using designed experiments. John Wiley \& Sons.

[14] Maren AJ, Harston CT, Pap RM (2014) Handbook of neural computing applications. Academic Press.

[15] Witek-Krowiak A, Chojnacka K, Podstawczyk D, Dawiec A, Pokomeda K (2014) Application of response surface methodology and artificial neural network methods in modelling and optimization of biosorption process. Bioresource technology 160:150-160. DOI:10.1016/j.biortech.2014.01.021

[16] Du KL, Swamy MN (2013) Neural Networks and Statistical Learning. Springer Science \& Business Media.

Submitted: $\quad$ 15.7.2016

Accepted: $\quad 05.10 .2016$
Hossein Rafizadeh

Department of Mechanical Engineering, Majlesi Branch, Islamic Azad University, Isfahan, Iran

Farhad Azimifar

Department of Mechanical Engineering, Majlesi Branch, Islamic Azad University, Isfahan, Iran

Puya Foode

Department of Mechanical Engineering, Isfahan University of Technology, Isfahan, Iran

Mohammad Reza Foudeh

Daneshpajoohan Higher Education

Institute, Mechanical Engineering

Department, Esfahan, Iran

Mohammad Keymanesh

Department of Mechanical Engineering,

Golpayegan University of Technology,

P.B.: 87717-65651, Golpayegan, Iran 